\title{
DESENHO DA PAISAGEM E APROPRIAÇÃO DO MEIO AMBIENTE
}

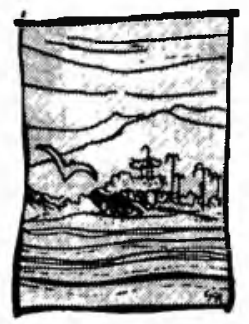

FANY CUTCHER GALENDER

O presente texto pretende discutir algumas questões relativas ao desenho da Paisagem através do relacionamento Ho mem/Natureza e da evolução das formas de atuação do planejador da Paisagem.

A Paisagem é entendida como a resultante da articulação dos processos naturais com as condicionantes sócioeconômicas e culturais. De acordo com Maria Angela F. Pereira Leite $(1992,1)$ "Aos muitos lugares e elementos que compõem uma Paisagem são atribuídos valores específicos que mudam constantemente, acompanhando a evolução dos padrões culturais. Estes estão, por sua vez, fortemente enraizados nos processos naturais de cada lugar ou região, isto $e$, a natureza e a cultura juntas como processos interagentes, conferem forma e individualidade aos lugares. Os ritmos de produção, transporte e consumo, por exemplo, interagem com os ritmos climático, hidrológico e biológico para moldar uma Paisagem cujos padrões de produção e utilização variam de acordo com o contex to específico da sociedade".

Mais ou menos idealizada, a tentativa de organizar o entorno é uma necessidade observada no decorrer de toda a história da humanidade. Para tanto, considerase imprescindível uma rápida observação da evolução das formas de ocupação e tratamento dos suportes físicos, para posterior compreensão da postura dos agentes que atuando, hoje, sobre estes espaços, refletem a história da relação Homem/Natureza, permeada pelas sucessivas transformações tecnológicas e culturais.

Se, inicialmente, observa-se a significação simbólica e religiosa da vegetação nas culturas egípcia e persa, além de uma vinculação original com as práticas agrícolas, nota-se uma crescente evolução no sentido de estilização e da formalização do entorno da habitação real, onde não só a amenização das condições climáticas eram perseguidas, como também as atividades ligadas à fruição estética e sensorial dos elementos que estruturavam estes espaços (com destaque para os tanques, canais e jatos d'água).

$\mathrm{Na}$ Espanha, através da invasão moura, o jardim, tal como os acima mencionados, expressa uma identificação do Paraíso. Cinco dos sete paraísos descritos no Corão, seriam jardins, de acordo com Tobey $(1973,88)$. 
A história do jardim italiano, em seu apogeu, confunde-se com a própria evolução da Arquitetura italiana. Nas Villas, as alamedas de ciprestes eram uma imitação das colunatas, indicando que o elemento vegetal tinha a função de elemento construtivo, arquitetônico, tais como escadas, peitorís, cascatas, pavilhões e pisos. Tal situação fica ainda mais evidente devido à prática excessiva da topiara, da imposição da geometria sobre o crescimento da vegetação.

Segundo Michael Laurie $(1976,24)$, no caso da Villa Lante e Villa D'Este "...há uma inspirada combinação de lugar (site) e conceito (concept). As qualidades do lugar são respeitosamente modeladas em uma forte composição arquitetônica. Isto proporciona um intenso contraste entre as formas naturais e as criadas pelo homem, o que é sempre essência da satisfação visual no desenho da paisagem" Tal colocação enfatiza a intenção primeira de construção da paisagem, quer pela apropriação do sítio, quer pelo aspecto imprimido aos elementos do projeto paisagístico, especialmente à vegetação, conforme anteriormente exposto.

Esta maneira de encarar a paisagem dissemina-se pela Europa, inclusive na França, culminando com os jardins planos (e não mais nas colinas e encostas, como na Itália) e de escala muitas vezes ampliada.

A unidade de medida não é mais o ser humano, o indivíduo, mas o grupo de cortesãos. Le Nôtre retorna o princípio italiano dos eixos, rígidas proporções e simetria e perspectiva infinita, refletindo o poder do homem sobre os outros homens (o poder absolutista, de caráter divino, da Coroa) e o poder do homem sobre a natureza, atingindo sua expressão máxima em Versalhes.

Já na Inglaterra, há o afastamento cada vez maior dos rigores e formalismos italiano e francês, graças às suas condições políticas e econômicas peculiares (democracia e efeitos da Revolução Industrial), bem como as condições físicas propriamente (colinas, rios sinuosos, etc.), aproximando-se de um ideal romântico ligado à literatura e à pintura.

A observação da natureza gera uma estética que, banindo a geometria renascentista, procura uma vinculação entre o humano e uma natureza remota, perdida. Os processos de cercamentos e a evolução urbana, que se segue na Inglaterra, são expressos na poesia de diversos autores, nos quais Raymond Williams $(1989,197)$ percebe manifestações da perda do "velho campo" a perda da "natureza" de "natureza intata", expondo "... a separação entre a natureza e a realidade do trabalho que a cria, e, em seguida, a decomposição da natureza, em relaçōes entre os homens alteradas de modo a se tornarem insuportáveis"

Sucedem-se propostas que apresentam maior uniformidade no tratamento da paisagem, com grandes extensões de áreas gramadas (Capability Brown); outras que reintroduzem a variedade de elementos, como terraços e flores (Rep- 
ton/Picturesque); tentativas de síntese do "melhor do Paisagismo" de todos os tempos e lugares (Loudon/Gardenesque); máxima informalidade no plantio com associação fortuita das plantas, de uma maneira muito próxima da pintura (G. Jekill).

A partir da Renascença, inicia-se a abertura eventual dos jardins da Coroa e da nobreza ao público, especialmente em Londres e algumas outras grandes capitais européias.

Com o aumento populacional das cidades e as profundas mudanças tecnológicas, a paisagem urbana adquire novos contornos, juntamente com o surgimento de distintas necessidades e atividades humanas.

Com base nesta revolução social e urbana, aparecem novas teorias e movimentos pela criação de parques voltados às atividades de recreação e lazer nas grandes cidades européias e norte-americanas, introduzindo as noções de apropriação coletiva e de caráter público aos grandes espaços livres urbanos vegetados. Em decorrência da consolidação da atividade projetual, frente a estas novas reivindicações da sociedade, surgem os "Arquitetos da Paisagem" (Landscape Architects), do desenho dos parques e do conceito de sistema de parques e sua inserção no planejamento urbano.

No Brasil, com a transferência da família real para o Rio de Janeiro, no séc. XIX, desencadeia-se um processo de formação de passeios públicos, praças e parques, concomitante à fundação de jardins botânicos com viveiros para pesquisa e reprodução de mudas de espécies de valor econômico e ornamental significativo. Anteriormente, temos em 1783 a construção do Passeio Público do Rio de Janeiro, projetado por Mestre Valentim, com base no Jardim Botânico de Lisboa e considerado não só a primeira grande obra de urbanização da cidade, conforme mencionado por Ottoni $(1972,5)$, como também o primeiro parque público do Rio de Janeiro.

Este mesmo passeio é remodelado por Glaziou, a mando de D. Pedro II, e, já com desenho mais curvilíneo, abandona seu traçado rigorosamente geométrico e retilíneo. Projeta ainda o parque da mansão imperial (a Quinta da Boa Vista), além da quase totalidade dos logradouros públicos e da arborização das avenidas do Rio de Janeiro.

Em São Paulo, a característica de "arraial sertanista" perdurou até o início do séc. XIX, sendo suas praças públicas modestas e mal cuidadas, destacando-se somente o Pátio do Colégio, a Sé e a Praça da Câmara Municipal.

Quanto ao jardim residencial, em realidade, pequenos quintais para cultivo de espécies frutíferas e criação de aves e animais domésticos, no final do século passado, torna-se objeto de grande atenção com o surgimento dos palacetes e a 
adoção de recuos e jardins laterais, que segundo Ottoni $(1972,27)$ criaram "um conjunto de edificações mais arejado e colorido, em relação ao casario que justapunha entre si, sem espaços intermediários, na antiga parte central da cidade" É importante ressaltar a importância destes jardins privados, em função de seu porte e qualidade, alterando a percepção da paisagem de certos setores da cidade de São Paulo, no que se refere à organização do espaço livre de edificação, evidenciando ainda mais a ausência de tratamento do espaço público.

Visando o atendimento da demanda de recreação e o controle das cheias dos bairros circunvizinhos, são criados o parque D. Pedro e o parque Anhangabaú, sendo este último baseado no projeto de Bouvard, arquiteto francês, que a pedido da Câmara Municipal, elabora uma proposta que apresenta duas diretrizes básicas: a valorização de três importantes marcos urbanos: o Teatro Municipal, o Vale do Anhangabaú e um conjunto de edifícios institucionais com implantação prevista na atual Praça da Sé e Pátio do Colégio e a revisão do sistema viário central e sua ligação com a periferia.

Os arquitetos Bouvard e Cochet dão tratamento paisagístico nitidamente europeu ao centro de São Paulo, que começa a se desenvolver com o incremento da cultura cafeeira, destacando-se o uso de grandes figueiras e pelo "imponente pórtico curvo de palmeiras imperiais" no Vale do Anhangabaú (Vegetação Significativa do Município de São Paulo, 1988, 76).

Observa-se, a partir do início deste século, intensa atividade de arborização das vias públicas, juntamente com o ajardinamento e manutenção dos espaços livres urbanos, por iniciativa do Poder Público Municipal.

Este breve relato das diferentes posturas no tratamento dado à questão da construção da paisagem ao longo do tempo, visa exemplificar, através dos mais destacados momentos históricos, o desequilíbrio na relação Homem/Natureza, tão bem sintetizado por McHarg (1971), quando este compara as diversas atitudes humanas perante a questão: a cultura islâmica, colocando a intenção de criação do Paraíso na Terra (o homem como criador e administrador); a visão ocidental, baseada na superioridade humana, que, negando a unidade, a interação com a natureza, preocupa-se somente com a conquista e exploração e, finalmente, a visão oriental, que, apesar de considerar Homem e Natureza indivisíveis, desconsidera o primeiro em sua individualidade e direitos.

Este enfoque é também o pressuposto da posição adotada por Anne Spirn (1984), ao identificar a necessidade de criação de parques e jardins em meio urbano, decorrente da visão da cidade como algo distinto da natureza; a cidade não como uma parte da natureza, implicando na tentativa constante de inserção de elementos "naturais" em meio urbano. A autora cita, ainda, exemplos de ci- 
dades que se adaptaram "engenhosamente" à natureza, distribuindo seus espaços livres de maneira a criar adequados sistemas de captação e drenagem de água, eficientes contra enchentes; filtros; áreas de produção de madeira e energia; recreação e retiro.

Quanto às possibilidades do desenho urbano, Anne Spirn coloca que "o meio ambiente de uma cidade e sua forma urbana, tomadas juntas, compreendem um arquivo de interação constante entre processos naturais e intenções humanas. Juntas, contribuem para a identidade única de cada cidade" (p. 12). Tal postura é endossada por L. Halprin $(1979,4)$, em seu conhecido artigo sobre a percepção coletiva das cidades, quando afirma que "a cidade vive em seu entorno paisagístico (landscape environment). Cada cidade brota da natureza da paisagem que a envolve - as rochas com que foi construída suas características geológicas e sua paisagem natural. Isto mais que qualquer outra concede-lhe o caráter original, a essência de sua personalidade, a quintessência de seu uso... Estas situações imprimem para sempre a qualidade de vida dentro da cidade, como as pessoas sentem-se vivendo nelas"

À outra colocação de Halprin, no início do mesmo artigo, sobre a vinculação de uma cidade à paisagem de seus espaços abertos, em oposição às suas edificações, soma-se a de Dan Kiley $(1982,19)$, que face ao crescimento das situações de urbanização, conclui que "... os espaços abertos e as ligações entre eles tornam-se cruciais. Espaços abertos, e espaços verdes, como partes integrais e não adicionais da estrutura urbana podem fornecer compensações às pressões urbanas e à ligação da cidade" Esta visão já era destacada por McHarg $(1971,57)$, para quem "a urbanização provoca aumento de densidade e crescimento da periferia, sempre às expensas do espaço livre" ressaltando a necessidade de superação da dicotomia entre soluções exclusivamente urbanísticas, arquitetônicas ou paisagísticas.

Diante destas colocaçōes, a reflexão sobre a Paisagem Urbana, deve considerar a evolução dos instrumentos de domínio humano sobre a natureza. não somente limitando-se à oposição entre Homem e Natureza, mas incluindo as condicionantes funcionais, técnicas, estéticas e culturais, reais e atuais. transpondo para o desenho, a dialética da sociedade em que se insere o espaço.

Considerando que o processo de mutação da paisagem envolve as transformações dos seus elementos constituintes (solo, água, vegetação, fauna, clima, espaços construídos, espaços livres e sociedade), apresentam-se três níveis de abordagem relevantes no planejamento da paisagem, independente de sua escala de intervenção: 
1. Funcional: Determinado pela sociedade humana, relativo ao aspecto de suprimento de suas necessidades produtivas, de abastecimento, energia, habitação, circulação, etc.

2. Ambiental: Referente à maximização da interação dos diversos ecossistemas envolvidos na intervenção. Diz respeito à capacidade de estabelecimento de uma dinâmica adequada entre o ecossistema humano e os demais.

3. Estético: Componente de caráter cultural, disseminado de diversas formas no interior de cada comunidade, com seus padrões, estereótipos e modismos.

A paisagem atual reflete o confronto entre as diversas instâncias que estruturam a sociedade, expondo as contradições e desequilíbrios sucessivos, gerando a aparente sensação de "caos", de desordem. Na realidade, de acordo com Maria Angela F. Pereira Leite $(1992,93)$ "intervenções e transformações são um processo contínuo de produção da paisagem, afetando todas as suas partes componentes. Este processo parece necessitar, cada vez mais, da integração entre o ecológico, estruturas culturais, modelo econômico e modelo de produção, para garantir condições adequadas de atendimento às necessidades de circulação, lazer, geração de energia, captação de água..."

Mais especificamente, além dos elementos constituintes que caracterizam um suporte físico e seus ecossistemas, é necessária uma avaliação dos padrões de ocupação em contraponto ao potencial (e desgaste) destes elementos, isto é, a revisão da relação que predomina nas intervenções humanas sobre o meio ambiente, apoiada, via de regra em grandes desmatamentos e alterações da morfologia do relevo, em condicionantes fundiárias (parcelamento do solo), na implantação do volume construído, em modelos de unidades habitacionais (seja de nível popular nas grandes cidades, seja em condomínios de alto padrão, verticalizados ou não), denotando sempre a criação de estereótipos vinculados às expectativas e às características sócioeconômicas do empreendimento. reiterando a imagem consagrada para cada situação. Mesmo a aplicação dos conceitos de área de preservação, conservação e transição deve ser considerada em cada contexto específico e não utilizado indiscriminadamente.

A história do urbanismo mostra a incessante tentativa de criação de um espaço harmonioso para a vida urbana, desde Camillo Sitte até os ditos progressistas, ligados à Carta de Atenas. como Le Corbusier. a Bauhaus e o Construtivismo russo, representantes mais expressivos desta corrente. Entre estes dois extremos, outra manifestação significativa foi a idealização das cidades-jardins, que através das propostas de Ebenezer Howard. vai procurar atuar na compra do terreno, financiamento do empreendimento e seu gerenciamento futuro, definindo inclusive o tamanho da população, dimensões e formas para a cidade-jardim. 
Todas estas posturas, bem como as decorrentes delas (Brasília, por exemplo), privilegiam a visão da cidade como um todo coeso e coerente que, seguindo esta ou aquela premissa, obterá a qualidade esperada. É do perfeito zoneamento, dos sistemas de circulação apropriados ou de dimensionamentos adequados que se chegará à paisagem urbana ideal. As possíveis "sugestões" fornecidas pelo meio ambiente são absolutamente ignoradas, em favor de modelos universais. Quanto aos modelos de implantação, formas de ocupação e desenho dos assentamentos humanos, endossando a visão modernista preponderante na atuação arquitetônica das últimas décadas, temos a repetição de padrões urbanos reproduzidos indiscriminadamente, em áreas com ecossistemas e condições sócioeconômicas e culturais distintas.

Uma reformulação conceitual, baseada na heterogeneidade e na diferença, seria mais adequada ao estabelecimento desta tão ansiada relação equilibrada entre homem/natureza. Segundo David Harvey $(1992,19)$ "... o modernismo universal tem sido identificado com a crença no progresso linear, nas verdades absolutas, no planejamento racional de ordens sociais ideais, e com a padronização do conhecimento e da produção" Ainda no mesmo texto. este autor discorrendo sobre a postura pós-moderna ressalta que "a fragmentação, a indeterminação e a intensa desconfiança de todos os discursos universais ou (para usar um termo favorito) totalizantes são o marco do pensamento pósmoderno"

Apesar das eventuais implicações e suspeitas que a expressão "pós-moderno" acarreta, é importante a discussão que a questão vem promovendo e os possíveis rebatimentos no âmbito do problema ambiental, na medida em que permite o questionamento de padrões e conceitos extremamente obsoletos e ineficazes.

Talvez, a melhor síntese ainda é fornecida por McHarg (1971), ao afirmar que é essencial o entendimento da cidade como uma forma derivada, em primeira instância. da evolução geológica e biológica, existindo como uma síntese de processos naturais feita pelo homem, sendo também imprescindível, perceber o desenvolvimento histórico da cidade como uma seqüência de adaptações culturais refletidas no plano da cidade e de seus edifícios. em uma interação entre forma dada (given): a identidade natural e a forma feita (made): a cidade criada.

\section{BIBLIOGRAFIA}

HALPRIN, Lawrence. The collective perception of cities. In: Urban open spaces. New York: Rizzoli, 1979.

HARVEY, David. Condiçāo pós-moderna. São Paulo: Edições Loyola. 1992. 
LAURIE, Michel. An introduction to landscape architecture. London: Pitman. 1976.

LEITE, Maria Angela Faggin Pereira. Novos Valores: Destruição ou Desconstruçāo? Questōes de Paisagem e Tendências de Regionalização. São Paulo. 1992. Tese (Doutoramento) FAUUSP

MARX, R. Burle. Arte e paisagem. Conferências escolhidas. São Paulo: Nobel. 1987.

MCHARG, Ian. Design with nature. New York: Dobleday. 1971.

OTTONI, Dácio Araújo Benedicto. São Paulo / Rio de Janeiro, Séculos XIX e XX. Aspectos da formaçāo dos seus espaços centrais. São Paulo, 1972. Tese (Doutoramento) - FAUUSP.

SPIRN, Anne W. The granite garden. New York: Basic Books. 1984.

TOBEY, George B. A History of landscape architecture. New York: American Elsevier. 1973.

WILLIAMS, Raymond. O campo e a cidade. São Paulo: Cia. das Letras. 1989.

Revista PROCESS: ARCHITETURE n. 33: Dan Kiley. Tokyo. 1982

Vegetação Significativa do Município de São Paulo.

- Série Documentos. SEMA / SEMPLA. 1988

Notas de Aula / Disciplina AUP. 836: Meio Ambiente Humano e Planejamento da Paisagem. 